
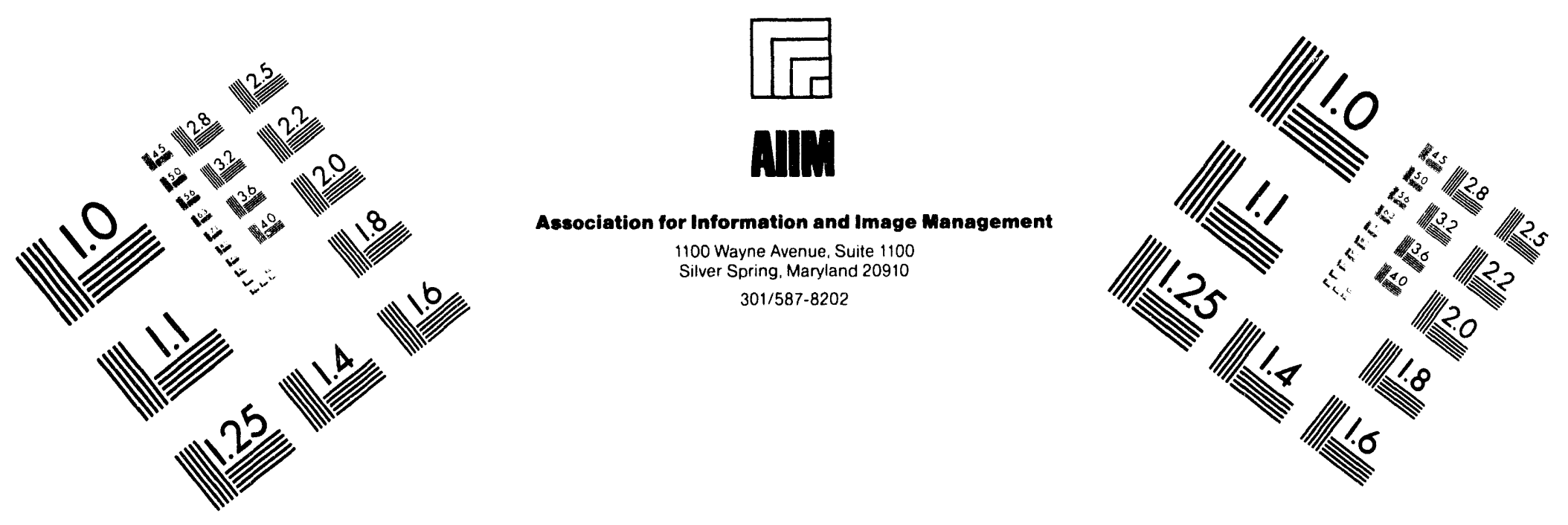

\title{
Centimeter
}

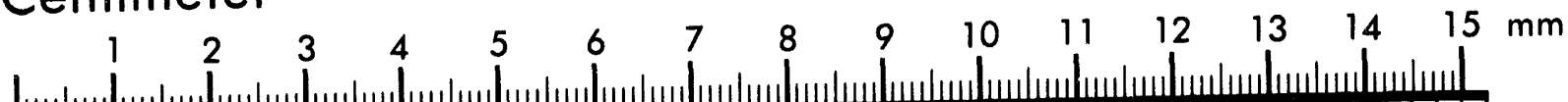
L Inches

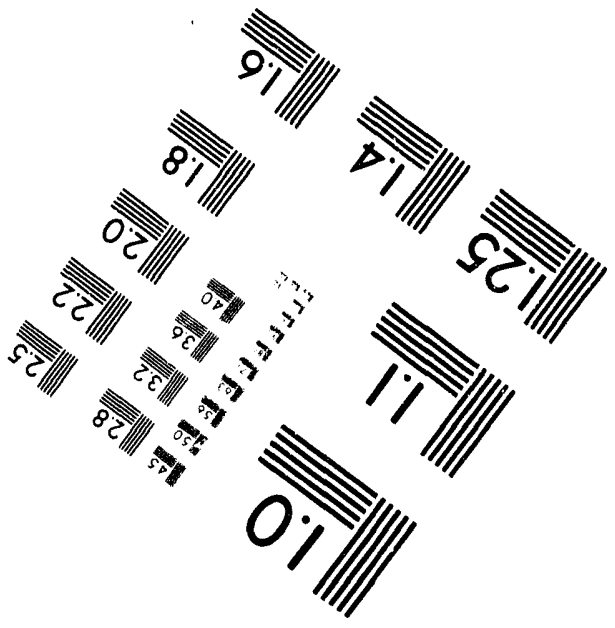

MANUFACTURED TO AIIM STANDARDS BY APPLIED IMAGE, INC.

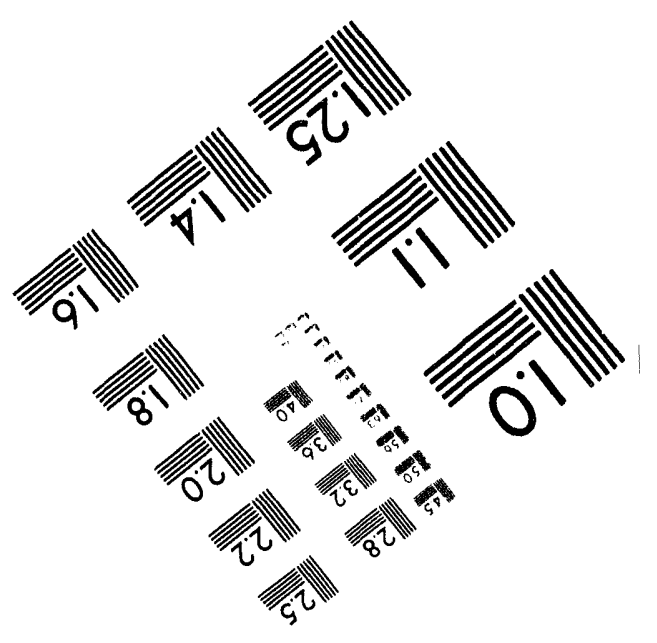



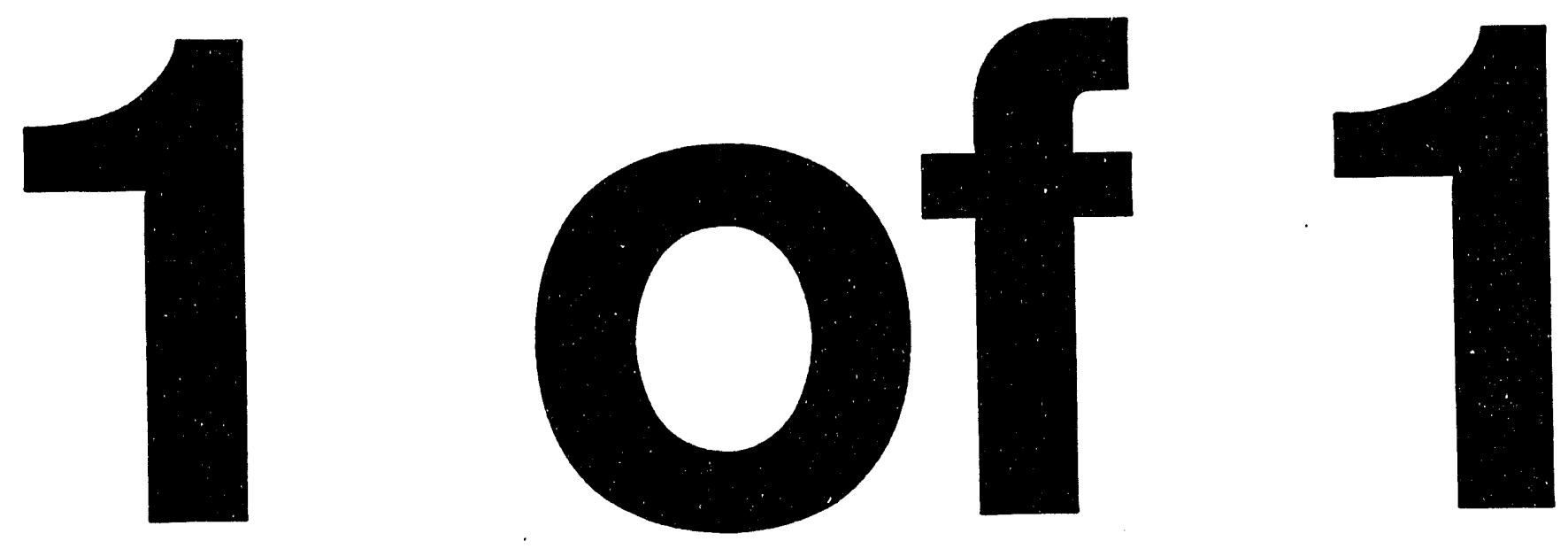


\section{Manufacturing Technology}

SANDIA NATIONAL LABORATORIES - Albuquerque, NM • Livermore, CA • Operated by Sandia Corporation for the U.S. Department of Energy

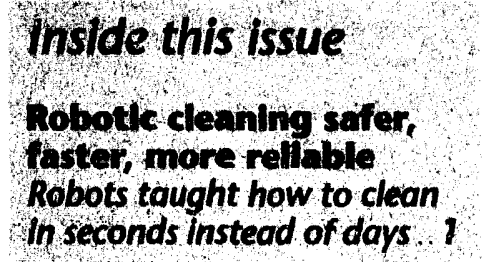

Hifnufacturing news in 2

Horoponous insulating

iilus can boost

milenodreutt performance

Filins display improved

dielectric constant,

mechanical properties....4

Hifo-cycle analysis:

the blg plature

Crodle-to grave

environmental

analysis tailored

to the needs of

defense manu,

focturing ..... 6

New simulation

tool predicts

propertles of

forged metal

Internal state

variable model

improves design, speeds

development time

\section{Robotic cleaning safer, faster,} more reliable

Robots taught how to clean in seconds instead of days

$\mathrm{A}_{\mathrm{t} \text { arm comes to life inside a glass and stainless-steel booth. Emerging from }}$ its rest bracket, it swivels and grips a printed-circuit board. After it shuttles the board to the part-mounting fixture, the arm grips a nozzle and begins spraying a cleaning solution. It directs the spray along a precisely predetermined path around each surface-mounted chip and into the hair-thin clearances between the chips and the mounting board.

This dextrous robotic printed-circuit cleaner, driven by a program developea by Sandia's Automated Component Cleaning project team, promises to reduce human exposure to hazardous solvents, shrink the waste stream, and improve the quality of the cleaning process.

Equally significant is the speed with which the robot arm can be programmed. "Manually planning and programming
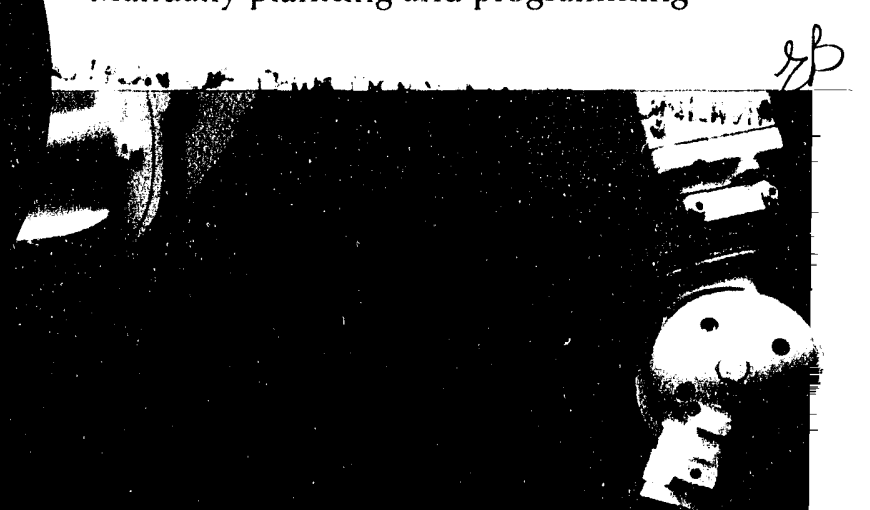

In an experimental cell in Sandia's Intelligent Systems and Robotics Center, a robot arm positions an integrated circuit on a fixture and then applies a cleaning solution (inset) according to preprogrammed path and spray parameters. 


\title{
Manufacturing news in brief
}

Advanced Manufacturing Day features product realization

Aglle welding cell integrates robots, process control, and network access

Dynamic stress analysis on a workstation instead of a Cray

SHIELD Reliability-TestLab-on-a-Chip wins RED 100 award

\author{
Sandia helps local \\ manufacturer bag \\ sticky problem
}

"ShowMe" conferencing application integrates Sandia-developed software

Sandia hosted an Advanced Manufacturing Day as part of the Ideas in Sclence and Electronics' 94 Exposition in Albuquerque on May 17. The half-day event's theme was "Product Realization - Partnership for the Future," and it featured 60 technical and business-oriented exhibits staffed by knowledgeable Sandians. More than 3,000 visitors from industry, academia, and government toured the exhibits. Bill Alzheimer, Org. 2900, (505) 844-8035, fax 844-5422

Process engineers recently demonstrated real-time monitoring and control of precision gas tungsten arc welding and pinch welding in a robotic cell at Sandia/Callfornia's new integrated Manufacturing Technologies Laboratory. The agile welding cell is linked by Ethernet to other manufacturing cells in the IMTL, notably a milling center and a machining cell; all can be accessed remotely to explore novel uses of computer netwotks for manufacturing.

Robert Hillaire, Org. 8205, (510) 294-2619, fax 294-2999

Solid model and dynamic stress analysis may no longer require specialized analysts and supercomputers thanks to. ACCORD, a Sandia-designed process for choosing mechanical engineering software. Using programs supported by ACCORD, engineers calculated stresses in the failed door hinge of a leadshielded forklift truck. Taking less than a week, the analysis included 50 hours of workstation computer time and cost much less than a conventional main frame approach.

James Schulze, Org. 5165, (505) 844-4706, fax 844-8745

The innovative SHIELD Reliability-Test-Lab-on-a-Chip garnered one of seven R\&D 100 awards presented to Sandia this year. SHIELD test structures, fabricated on the same wafer as the functional integrated circuits, replicate the excltation functions of expensive external reliability testers. With only DC voltage applied, SHIELD generates its own high-frequency signals and high temperatures on-chip to stress its neighborting circuits. Because SHIELD employs the same technology as the ICs being tested, it eliminates the expense and delays of replacing or upgrading specialized external reliability testers as technologies advance. Whilam Miller, Org. 2276, (505) 844-7161, fax 8442991, or Eric Snyder, Otg. 2276, (505) 845-8577, fáx 844-2991

Roses Southwest Papers of Albuquerque, a regional supplier to McDonald's restaurants, had processing problems related to gluing McDonald's carryout bags made of recycled paper. Sandia's Pete Stromberg, funded by the Labs' small-business technology transfer program, helped Roses pinpoint and remedy the problem by installing capacitive proximity sensors to monitor glue dispensing.

Pete Stromberg, Org. 2484, (505) 844-0829, fax 844-1110

A licensing agreement between Sandia and Sun Microsystems has led to Sun's marketing an upgraded conferencing software product called ShowMe 2.0. It features audio and video capability as well as Sandia's application-sharing technology from the Interactive Collaborative Environments project. In an on-line conference, remote computer users can view common images, discuss issues, edit files, do "what if" exercises, and modify designs - all in real time.

James R. Yoder, Org. 1090, (505) 845-9045, fax 844-4105 
the cleaning path takes several hours, or even several days for complex parts. This essentially relegates automated cleaning to highvolume production situations," says project leader Bill Drotning of Sandia. "Our approach can generate the required robot-motion programs automatically in seconds. This will bring robotic cleaning within the reach of the small-lot manufacturer."

Drotning and his coworkers developed this automated robot programmer, under sponsorship of DOE's Office of Defense Programs, to enable the use of alternative solvents at AlliedSignal in Kansas City, a major DOE production facility. At AlliedSignal, operators have traditionally hand-sprayed trichloroethylene and chlorofluorocarbon solvents to remove rosin flux, organic and inorganic contamination,

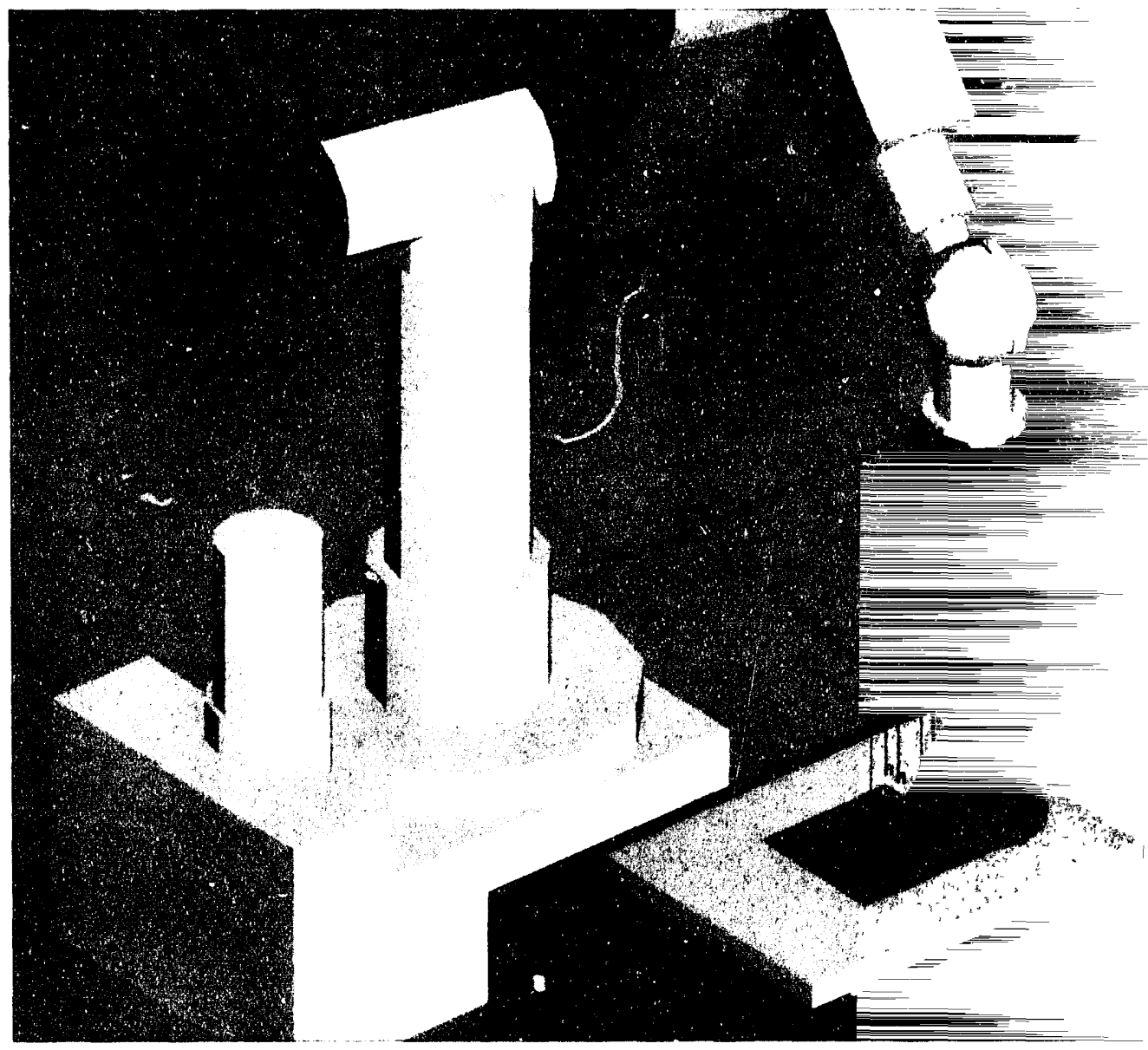
and particulates from small electronic components and subassembiies.

Efforts are under way industry-wide to develop environmentally benign alternatives to the use of chlorinated solvents for cleaning. However, many alternative cleaning agents take much longer to achieve equivalent cleanliness. Longer cleaning times make manual spraying less reliable and make the automated approach more attractive, since it can ensure spray uniformity, consistency, control, and repeatability over any length of time without operator boredom and fatigue.

The team's program uses the computer-aided design model of the printedcircuit board as well as a cleaning process knowledge base to automatically instruct the robot. In seconds, the program plans the path that the robot arm will follow. The process engineer can specify parameters such as nozzle speed, standing time, standoff nozzle distance, spray pattern configuration, and how many iimes the robot arm should repeat the edge-spraying action. The program uses this process, along with the CAD model of the part, to automatically generate instructions to the robot in the robot's native language. The same information also creates an animated graphical simulation to verify path planning to process engineers.

The project team predicts far-reaching effects for the technology they have developed. "The software development showcased in this project will add to the technology base for CAD-based path planning and automated programming of robotic systems so that these techniques can be used for many manufacturing processes - not just cleaning," concludes Drotning. $由$

In addition to using the CAD model of the integrated circuit to automatically instruct the cleaning robot in its own language, Sandia's program creates an animated graphical simulation of the cleaning process to verify its path planning. 


\title{
Microporous insulating films can boost microcircuit performance
}

\author{
Films display improved dielectric constant, mechanical properties
}

\begin{abstract}
$\mathbf{M}$ icroelectronics developers have made remarkable strides in their quest for ever faster, ever smaller, ever higher-performing microcircuits. Breakthroughs such as advanced lithographic techniques, substrates with low dielectric constants and high thermal conductivity, submicrometer linewidths, and multichip module packaging are all advancin; ; the state-of-the-art at a dizzying pace.

Sandia researchers have added a new item to the list - microporous insulating films that may permit better microcircuit packaging and further performance improvements. Microcircuit performance is limited by the propagation speed of the electrical signals in conductors that interconnect components. Propagation speed is inversely proportional to the square root of the dielectric constant of the electrical insulation that separates conductors. The dielectric constant also affects the size of a microcircuit. A lower dielectric constant reduces the capacitance between adjacent conductors, thus reducing cross talk (electronic noise) and allowing closer conductor spacing, reduced device dimensions, shorter conductors, and a resultant further increase in propagation speed.

For many microelectronic applications, developers have reduced the insulator dielectric constant by switching from inorganic insulators (dielectric constant of 10 to 11 ) to organic polymer insulators such as polyimide
\end{abstract}

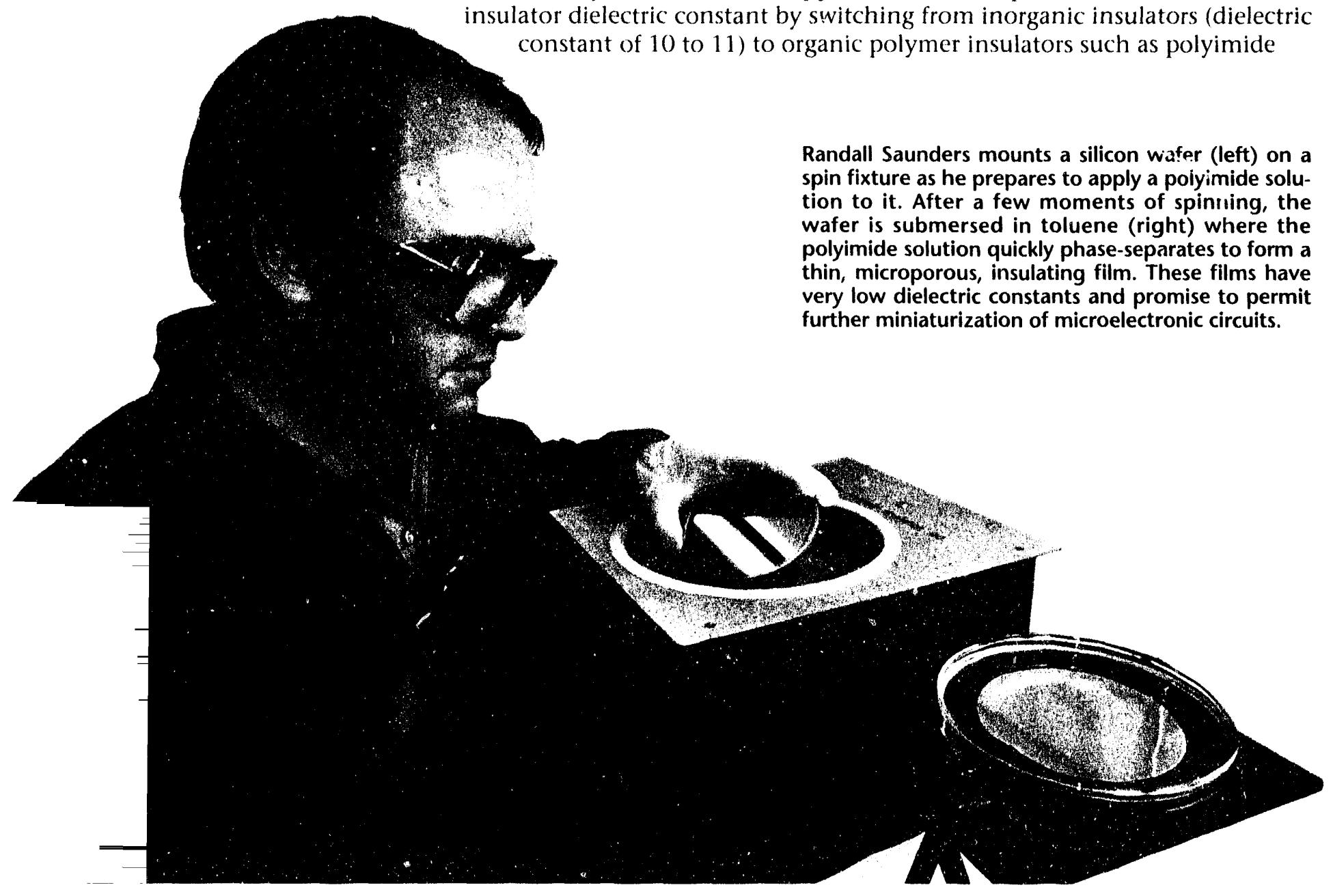


(dielectric constant of 3 to 4 ). Compared with their inorganic counterparts, however, solid polyimides do not conduct heat as well and they expand more when heated.

A Sandia team, internally funded by the laboratorydirected R\&D program, has developed a way to reduce the dielectric constant of polyimides and improve some of the mechanical properties that have impeded penetration of polyimide insulators into the microcircuit packaging markets. The team, led by chemical engineer Randy Saunders, has shown that polyimide films having small, uniform pores can be deposited onto electronic devices. "The porosity means that a significant amount of the film is filled with air, which reduces the film's dielectric constant," reports Saunders. "In addition, this

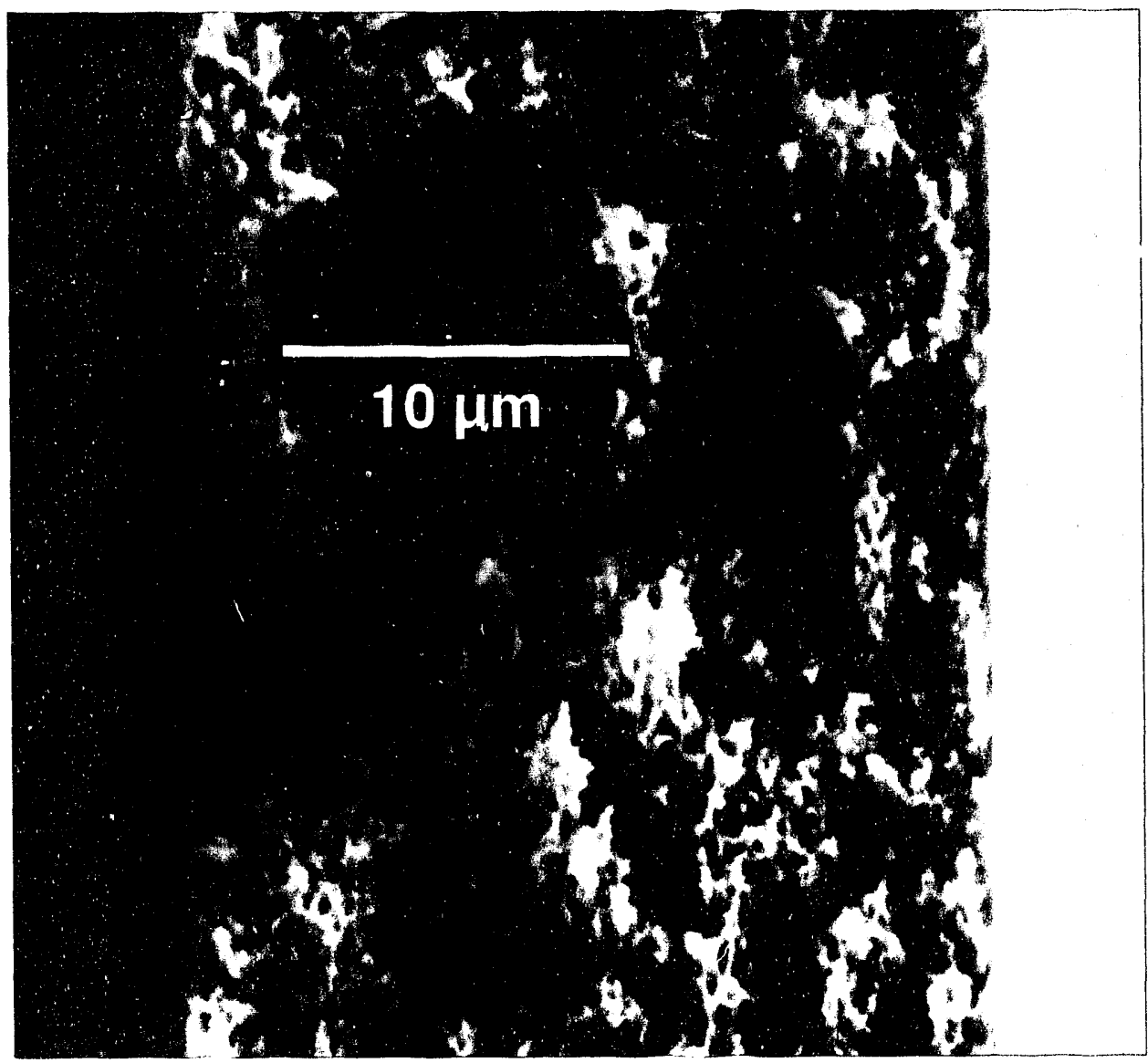
film's foam structure has a smaller overall thermal expansion coefficient than solid polyimide. This foam structure reduces surface stress felt by the circuit substrate, thus reducing structural interface failures."

The Sandia approach is based on a thermodynamic technique called nonsolvent-induced phase separation, which polymer chemists commonly use to purify polymers. To make the insulating film, Saunders and his coworkers dissolve polyimide and apply the solution to a rotating silicon wafer; then they immediately submerse the coated wafer in a bath of a liquid, such as toluene, that is not a solvent for the polymer. This causes the polymer to phase-separate out of solution quickly as a thin film with the desired uniform microporous structure.

To date, Saunders' team has made uniform films as thin as 8 micrometers, with average pore size as small as 0.3 micrometers, and porosity ranging from 25 to 75 percent. One of the films recently produced has a measured dielectric constant of 1.88 , about half that of solid polyimide film. Stress tests confirm that these microporous films do reduce surface stresses by more than a factor of 10 . Thermal expansion measurements are currently under way.

"For microelectronic packaging and interconnects, 8-micrometer films may be adequate," observes James Aubert, manager of Sandia's Organic Materials Processing Department. "But, by adjusting processing parameters, we're pushing for the thinnest films we can get - maybe 1-micrometer films with pores smaller than 0.1-micrometer. These films could have a far-reaching impact on many aspects of the microelectronics industry." $\rightarrow$

For more information, call

Randall S. Saunders, Org. 1815, (505) 844-1760, fax 844-9624, or Jim Aubert, Org. 1815, (505) 844-4481, fax 844-9624.

Above is a $2,000 x$ photomicrograph of a cross section of a Sandia-developed microporous phase-separated polyimide film. This 20-micrometer sample has an average pore size of $\mathbf{0 . 6}$ micrometers. More recent work has produced films as thin as 8 micrometers, average pore size of $\mathbf{0 . 3}$ micrometers, and porosity ranging from 25 to 75 percent. 
"The need for a working LCA methodology is essential in today's economically competitive world and environmentally sensitive culture."

\section{Life-cycle analysis: the big picture}

\section{Cradle-to-grave environmental analysis tailored to the needs of defense manufacturing}

S andia engineers, using a new method to understand the impact of indus$\checkmark$ trial products on the environment, have recently completed the initial phase of a case study to further refine the technique. Called life-cycle analysis, this tool identifies processes that, if modified, could lessen harm to the environment. To identify these processes, analysts gather data on inputs (the energy and materials required to make a product) and outputs (waste, scrap, and by-products) and then assess the effects of both on ecosystems, human health, and natural resources. Costs are also considered - not only direct costs associated with design, manufacturing, and marketing, but also liability costs associated with noncompliance penalties, accidents, and quality of life.

"The power of LCA is that it gives you the big picture - all aspects of the product from cradle to grave," explains mechanical engineer Ken Tschritter of Sandia's Technology Applications Department. "The only limits on the breadth of LCA are the boundaries that the investigators might use." Adds Ben Odegard of the Engineered Materials and Processes Department, "The need for a working LCA technique is essential in today's economically competitive world and environmentally sensitive culture."

Analysts Tschritter, ()degard, and Don Adolphson (now retired) are conducting the life-cycle anilysis case study, which is funded by the DOE's Office of Waste Management. Thie study will focus on effects on the environment of the manufacture, use, and eventual decommissioning of a gas storage and transfer system for a weapon component. The case study was prompted by a request from the Environmental Protection Agency asking the DOE to explore using life-cycle analysis in its weapons production complex to minimize waste. So far, Sandia's life-cycle analysis of the gas transfer and storage system has identified many waste minimization opportunities at four DOE production sites. A major remaining challenge is to quantify the environmental impact of these findings and to determine the decisions that must be made before action can be taken.

While a fully functional life-cycle analysis procedure is not available today, the EPA is pursuing steps toward this end, and the DOE has further advanced the methodology at its national laboratories and production facilities. "Sandia, through its environmentally conscious manufacturing program, has made significant contributions to finding and implementing ways to minimize waste generated during manufacturing," observes Odegard. "However, LCA requires that environmentally conscious manufacturing be supplemented by environmentally conscious design. We have explored this concept in our case study of the gas storage and transfer system and we think that LCA methodology could go further to facilitate environmentally conscious design."

Other elements of life-cycle analysis that need more development include cost analysis, defining a means to detect and deter changes that negatively impact processes downstream, and a decision-making tool for implementing appropriate waste minimization and pollution prevention findings.

Sandia's analysts feel that one of their final challenges is to devise a meaningful way to package the input and output data. "This aspect is critical to the decision maker. We envision LCA being designed from the beginning with clear communication in mind," states Tschritter.

For more information, call

Ken Tschritter, Org. 8113, (510) 294-2971, fax 294-2999, or Ben Odegard, Jr., Org. 8714, (510) 294-2789, fax 294-3410. 


\title{
New simulation tool predicts properties of forged metal
}

\author{
Internal state variable model improves design, \\ speeds development time
}

$\mathbf{I}_{\mathrm{te}}^{\mathrm{n}}$ n the Middle Ages, Syrian metal workers developed sophisticated forging techniques to produce the legendary Damascus blade - a blade so keen that it could cut floating gauze, so hard that it could slice an iron spear as if it were a reed, and so elastic that it could be tent to a right angle and spring back to shape. The blade defied reproduction in Europe for centuries. Modern industry still uses forging - the shaping of metal (usually heated) by hammering or pressing, often into a hardened die - to produce superior hardness, microstructure, and resiliency in countless applications such as components for aircraft engines and vehicle transmissions.

Like the ancient forgers, modern forgers still rely heavily on operator and designer skill and expertise to produce high-quality forgings. Demands on modern forgers are, however, much greater. Automotive and aerospace manufacturers must mass-produce forged components reliably to survive, and they are constantly extending themselves to reduce the development time of forged components for new products.

Sandia researchers Doug Bammann, Paul Jin, and Ben Odegard are developing numerical simulations that promise to reduce much of reliance on operator expertise in forging processes with computer models, thereby providing manufacturers a powerful tool for competing in today's marketplace. "A component's strength and other material characteristics depend critically on initial properties of the forgings and in particular on the nonuniformities developed in the forging process," observes Odegard. "Our modeling capability will allow designers, engineers, and technicians to predict a material's response to forging by performing simple tests on the material before it is forged." The team has previously used this approach to predict material properties after other metal-working processes such as rolling and welding.

"What this model does is introduce state variables to try to account for the change of state: formation of subgrains - the refinement of grains that adds strength to the forged material," says Bammann. "Changes in these variables allow us to model hardening and recovery mechanisms that can reduce the rate of hardening." The internal state variable material model describes the hardening and large strainrate recovery of the matcrial. The model can also predict failure and strain localizations, which can occur from the effects of textural softening, thermal softening, and damage to the material due to growth and coalescence of voids.

The drawings depict increasingly complex forging configurations, which require increasingly sophisticated computer simulations to predict materials reactions and optimum forging parameters. Arrows show the direction of applied force. The top part is a simple upset forging requiring only an open die and low constraint. The part in the middle is a more complex upset forging requiring a closed die with lateral constraint only. A simulation would need to consider a linear strain gradient. The bottom part is a forward extrusion the severest of the forging processes - in which metal is forced to flow rapidly through an orifice and is highly constrained. Strain is extremely nonuniform and high degrees of strain localization and recrystallization may be present.

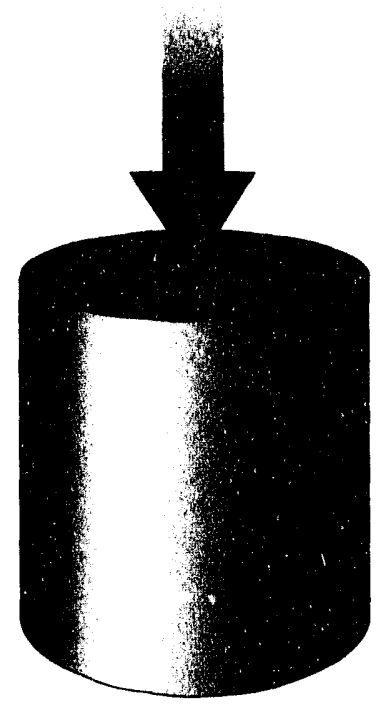




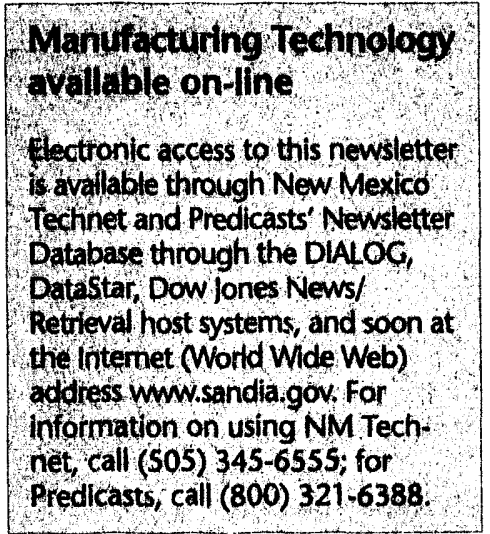

Sandia's forging process simulation promises to improve product design and manufacturing of forged components. "We expect designers to be able to run our simulation and use its results to decide exactly how hot the workpiece should be while it is being forged and at what rate it should be deformed," says Bammann. "Our simulation will also dramatically decrease the time required for designing forging dies." Today, manufacturers must determine forging parameters and design forging dies using expensive, time-consuming, trial-and-error techniques.

The forging model will also provide valuable real-time information during forging. "What we ultimately envision is a program running on a workstation right on the shop floor that would tell the operator how to adjust the forging temperature, deformation, and rates so that mechanical properties will meet specifications," says Bammann.

To date, the team has completed a "constitutive," or material response, model of $304 \mathrm{~L}$ stainless steel. Now they are investigating the effects of deformation, deformation rate, temperature, and friction on a single-stage forwardextrusion forging (the severest of the forging processes) and evaluating, both experimentally and numerically, the mechanical properties and nonuniformity of these properties in the workpiece.

Development of this forging simulation is currently being funded internally through Sandia's laboratory-directed R\&D program. However, this work has already attracted the attention of large forging users in the private sector. Reynolds Aluminum is using the model on a sheet-forming process. Also, a major U.S. manufacturer has expressed interest in a complex forging analysis and is presently negotiating a cooperative research and development agreement with Sandia. 团

For more information, call

Doug Bammann, Org. 8743, (510) 294-2585, fax 294-3410,

Ben Odegard, Jr., Org. 8714, (510) 294-2789, fax 294-3410, or

Paui jin, Org. 8742, (510) 294-1527, fax 294-3410.

\section{Manufacturing Technology is published by Public Relations and Com. munications, Sandia National Laboratories, to facilitate technology exchange with industries, universities, and government agencies. \\ Director: Jerry Langheim Technical consultant: William $E$. Alzheime Lead editor: Jim Leonard \\ Associate editors: Linda Doran, H. L. Floyd Bob Goetsch, Lori Parrott, Charles Shirley

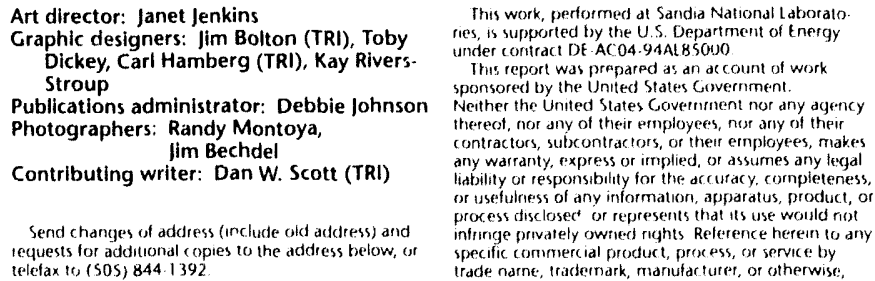

Send changes of address (include old address) and ries, is supported by the U.S. Department of Enetgy The ontract DE AC 04.94ALESOHOH Whe report was prapared as an ac count of work thesect, nor any of their employees, nes any of their contractors, stibcontractors, or their empioyfes, makes any warranty, express or ingshied, or assumes any legal or usetuliness of any information, aurratatus, product, or process disclosec or represents that its use would riot infurige grivately owived rights Reference herein to any specific commercial product, proxess, ar service by equests for additional copies to the address below, elefax io (SOS) 844.1392 \\ This work, performed at Sandia National Laborato Neither the United States Coveetrment nor any ayency}

dres not necessarily constitute or imply us endorsement. recommendation, or favoring by the United State Covernment, any agency thereof, or any of their expressed herein do not necessarily reflect those of the United States Covernment, any agency thereol, or any of their entractors or sube ontractors. Reprort number SAND94.1913. DOE Distritution Avaliable from

technic al Intormation Service.

S2Es Port Royal Ruad

springfield, Virçntra 2216
SANDIA TECHNOLOGY BULLETIN

Laboratory Communications Dept. 12610

Sandia National Laboratories

P.O. Box 5800

Albuquerque, NM 87185-0129
BULK RATE

U. S. POSTAGE

PAID

Albuquerque, New Mexico

Permit No. 232

address correction requested

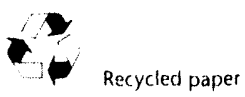

$|A L \cdot| B \cdot 7 / 94 \cdot 21000$ 

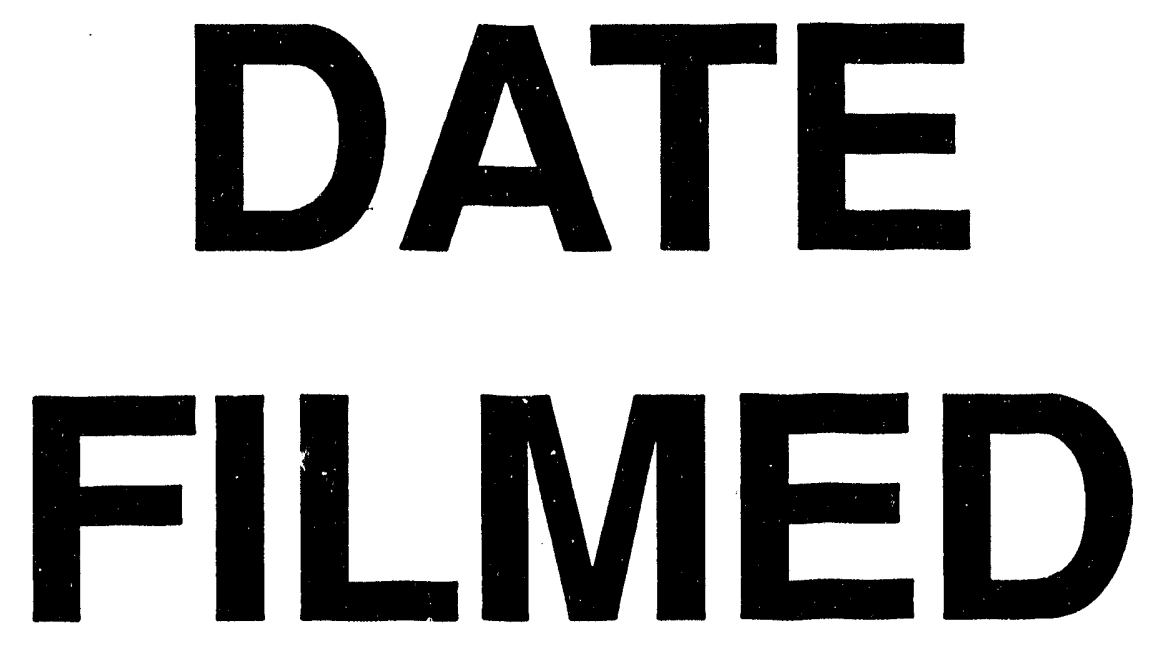

$$
10 / 18 / 94
$$
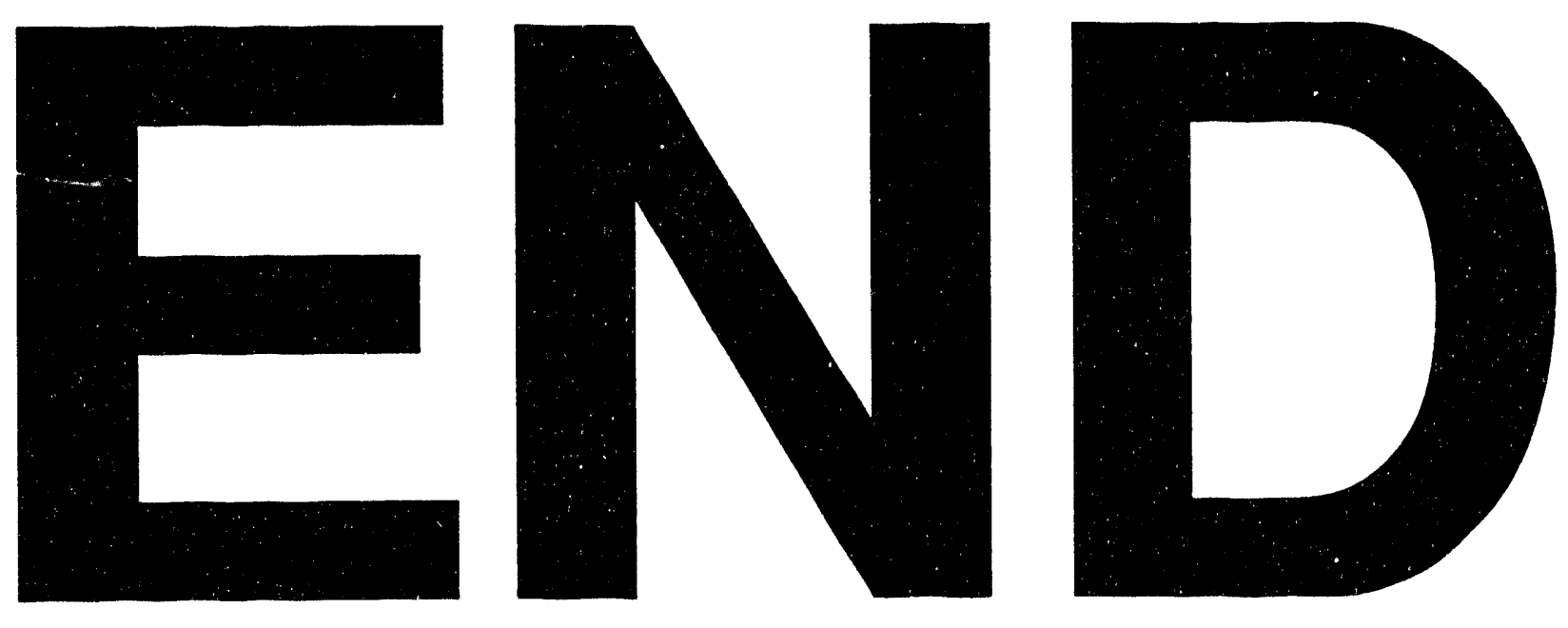
